\title{
CONSENSUAL QUALITATIVE RESEARCH ON FREE ASSOCIATIONS FOR COMPASSION AND SELF-COMPASSION ${ }^{1}$
}

\author{
JÚLIA HALAMOVÁ, MARTINA BARÁNKOVÁ, \\ BRONISLAVA STRNÁDELOVÁ, JANA KORÓNIOVÁ
}

\begin{abstract}
The aim of our study was to explore the first three associations for the following two stimulus words: compassion and self-compassion. In addition, we were interested in whether the participants would conceptualise these words more in terms of emotions, cognitions, or behaviours. The sample consisted of 151 psychology students. A consensual qualitative research approach was adopted. Three members of the core team and an auditor analysed the free associations of compassion and self-compassion. The data showed that there were four domains for both compassion and self-compassion: the Emotional, Cognitive, Behavioural and Evaluative Aspects of compassion/self-compassion. The only domains that differed were the Biological Aspect of compassion and the Situational Aspect of self-compassion. The most frequently represented domain for both compassion and self-compassion was the Emotional Aspect, while both more positive as well as negative emotions were associated with self-compassion than was the case with compassion. The findings of our study show that the participants perceived compassion as mainly consisting of empathy; the emotions of love, sadness and remorse; cognitive understanding; and behavioural displays of help, physical or mental closeness. Compassion was seen as being mainly directed at those close to them, such as family and friends, and at vulnerable people. Compassion occurs in situations of loss or any other kind of suffering. The participants viewed self-compassion primarily in terms of the positive emotions of love and calmness; the negative emotions of unhappiness, sadness and remorse; cognitive understanding; and behavioural displays of self-help through the provision of self-support and self-assurance. Self-compassion is triggered mainly in situations involving internal suffering caused by criticism or externally as a response to a difficult situation. Self-compassion is evaluated in both negative (because of its misuse) as well as positive terms (because of its connection to virtues). The findings of our qualitative study support the idea that compassion is a multidimensional construct consisting of emotional, cognitive, and behavioural aspects.
\end{abstract}

Key words: compassion; self-compassion; free associations; consensual qualitative research

\section{Introduction}

Compassion is an important human virtue in all major religions around the world, including Christianity, Judaism, Buddhism, Hinduism, and Islam (Balslev \& Evers, 2011). Karen

1 This article was supported by the VEGA Scientific Grant Agency under grant no. 1/0578/15. 
Armstrong even launched a "Charter of Compassion," a document and related web page motivating all humans to allow more compassion into their lives in order to build a better place for all people to live in (https://charterforcompassion.org). Similarly, Ekman and Ekman (2017, p. 41) have called for a global compassion not only in relation to those close to us but all human beings: "It would be a different world, a desirable world, if all of us felt global compassion, a concern to alleviate the suffering of anyone, regardless of their nationality, language, culture, or religion". Despite being rooted in religion, compassion is one of the most rapidly growing areas of interest in psychology, medicine, neuroscience, pedagogy, organisational science, ethics, and social work (Seppälä et al., 2017).

There has been a boom in quantitative research on compassion and self-compassion in various scientific disciplines in recent years (e.g., Duarte et al., 2017; MacBeth \& Gumley, 2012; Neff, 2003; Neff, Kirkpatrick, \& Rude, 2007). A meta-analysis by Zessin, Dickhäuser and Garbade (2015) found there was a significant positive relationship between selfcompassion and well-being. Compassion is an important factor in understanding mental health (MacBeth \& Gumley, 2012), and self-compassion is related to health-promoting behaviour in individuals, according to a meta-analysis by Sirois, Kitner and Hirsch (2014). Therefore, it is surprising to find that qualitative methodologies are rarely used to study these phenomena. So far, we have discovered only one qualitative study that focuses mainly on compassion (van der Cingel, 2011) and one on self-compassion (Pauley \& McPherson, 2010). Both these studies were conducted using healthcare samples and therefore have limited generalizability to other populations.

In addition, there is an ongoing debate as to what compassion actually is. Different scholars see compassion as very different constructs. For example Ekman (2003) sees it as the experience of empathic distress, for Sprecher and Fehr (2005) compassion is a special kind of love and not a distinct emotion, while others see compassion as a distinct emotional state (e.g. Haidt, 2003). By contrast, Jazaieri et al. (2013) and Strauss et al. (2016) perceive compassion as a multidimensional construct, not only as an emotional state but also as a phenomenon with cognitive and behavioural components. Furthermore Gilbert et al. (2017) see it as a sensitivity connected to motivation and helping behaviour.

Among those who see compassion as an emotion is Lazarus (1991, p. 289), who included compassion in his taxonomy of emotions: "Compassion...is not a sharing of another person's emotional state, which will vary depending on what the other person's emotional experience seems to be, but an emotion of its own...". The consequence of feeling compassion is to be moved and to want to help so as to end suffering. Similarly, Goetz et al. (2010), in their empirical review on compassion, concluded that compassion is an emotional state because compassion is connected to distinctive affective, expressive, and physiological characteristics.

By contrast, Ekman (2010) has argued that compassion cannot be considered an emotion. For Ekman (2010) the distinctive features of emotions are that they can be enacted constructively or destructively, emotions need not be cultivated, emotions twist perception, emotions can be out of control, and emotions are temporary; nonetheless he does not think compassion satisfies these criteria. However, we reject that, on the grounds that compassion fatigue (Figley, 1995) is an example of a destructive type of compassion, and in the extreme version hypersensitive people who have problems saying no are unable to control it. Anger 
management training is an example of altering emotions. Giving money to a masked beggar and then finding out the person was not a true beggar is an example of compassion distorting perception and of the transitory nature of compassion.

Some scholars (Jazaieri et al., 2013) perceive compassion as comprising cognitive (an awareness of the suffering), emotional (being emotionally moved by the suffering) and behavioural elements (wish to see the suffering relieved and helping). Strauss et al. (2016) suggested that compassion is a process with cognitive, affective, and behavioural components. Specifically, they (Strauss et al., 2016, p. 19) reported that compassion is created by the following five elements: 1) Recognising suffering; 2) Understanding the universality of suffering in the human experience; 3) Feeling empathy for the person suffering and connecting with the distress (emotional resonance); 4) Tolerating uncomfortable feelings aroused in response to the suffering person (e.g., distress, anger, fear), so remaining open to and accepting of the person suffering; and 5) Motivation to act/acting to alleviate suffering.

The first two of these elements are cognitive, while the second two are emotional and the last one is behavioural.

According to Neff and Germer (2013) self-compassion is merely compassion for oneself. The whole discussion about what compassion is therefore also relates to self-compassion and the answer is connected to both constructs.

\section{Research goals}

To the best of our knowledge, only in the two studies mentioned above (Pauley \& McPherson, 2010; van der Cingel, 2011) has a qualitative analysis been used to explore compassion and self-compassion. Consequently, very little is known about the words people associate with these constructs, how the terms are conceptualised, and how they are interpreted. For that reason, our goal was to identify and categorise associations linked to the words compassion and self-compassion.

Given the ongoing debate over what compassion is, we were also interested in whether our participants would conceptualise these words more in terms of emotions, cognitions, or behaviours.

\section{Methods}

\section{Sample}

The participants were psychology students at Comenius University in Bratislava. They were selected on the assumption they have better skills of mentalisation, greater experience of psychological constructs and in their future work they will require an understanding of subjective human experiences. Of the 151 participants, 37 were men. The mean age was 22.2 years $(\mathrm{SD}=4.4)$.

\section{Testing materials}

The participants were asked two open-ended questions "...without censoring, please write down the first three associations when you see the word compassion" and "...without 
censoring, please write down the first three associations when you see the word selfcompassion".

\section{Procedure}

The data was collected as a part of a larger questionnaire battery on self-compassion and self-criticism. The questions on the free associations came at the beginning of the questionnaires immediately after the informed consent form and the socio-demographic information.

\section{Data analysis \\ Consensual Qualitative Research}

According to Chambers (2002), qualitative approaches are prone to distortion, which can lead to the incomplete or unsystematic coverage of the data, selective selection owing to researcher perception or to disagreement among the group of researchers. To overcome these limitations, we used the Consensual Qualitative Research (CQR) method (Hill, 2012) in our study. The aim of this qualitative method is for the researchers to reach a consensus once the data categorisation has been performed separately by each researcher. A consensus is achieved through subsequent group discussions, with an auditor checking there is consensus in the later stages and through them all agreeing on the final categorisation of the data.

\section{Determining thematic areas}

Before starting to work on the data, the researchers completed the questionnaire according to how they expected the participants would answer. This was done to make sure their expectations were clear. Three assessors in the core team were given the participants' free associations for the words compassion and self-compassion separately. Individually each member of the core team labelled the domains and thematic areas in the text and assigned the free associations to them. Following the group discussion, the assessors agreed on the domains, subdomains, categories, and characteristics.

\section{Audit}

The auditor checked the domains, subdomains, categories, and characteristics agreed by consensus and gave the assessors feedback on the analysis. The auditor's comments were taken into account and acted upon.

\section{Results}

Four researchers performed a consensual qualitative analysis on the responses given by the 151 respondents in relation to the two stimulus words, and 742 coded statements were then identified. These described the free associations for compassion (391) and self-compassion (351). At the beginning of the analysis we all agreed to exclude associations which 
were irrelevant to the constructs being investigated and that had no connection to either compassion or self-compassion. There were 11 for compassion (e.g. grammar) and 15 for self-compassion (e.g. wood).

The coded statements were categorised under the 5 domains, 12 subdomains, 12 categories and 21 characteristics which were created for compassion or under the 5 domains, 12 subdomains, 17 categories and 14 characteristics created for self-compassion. The categorisation of the stimulus word compassion can be found in Appendix 1, including specific examples of participant statements. The categories for the word self-compassion can be found in Appendix 2. The most frequently represented domain for compassion is the Emotional Aspect of compassion ( $\mathrm{f}=187 ; 48.95 \%$ ). In terms of frequency the Behavioural Aspect of compassion ( $\mathrm{f}=83 ; 21.73 \%$ ) comes next, and the Biological Aspect of compassion

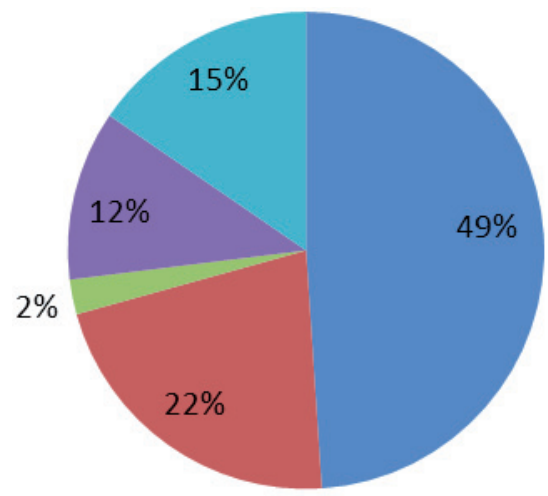

- emotional aspect

- behavioural aspect

- evaluative aspect

n cognitive aspect

- biological aspect

Chart 1. Percentage of each domain in compassion

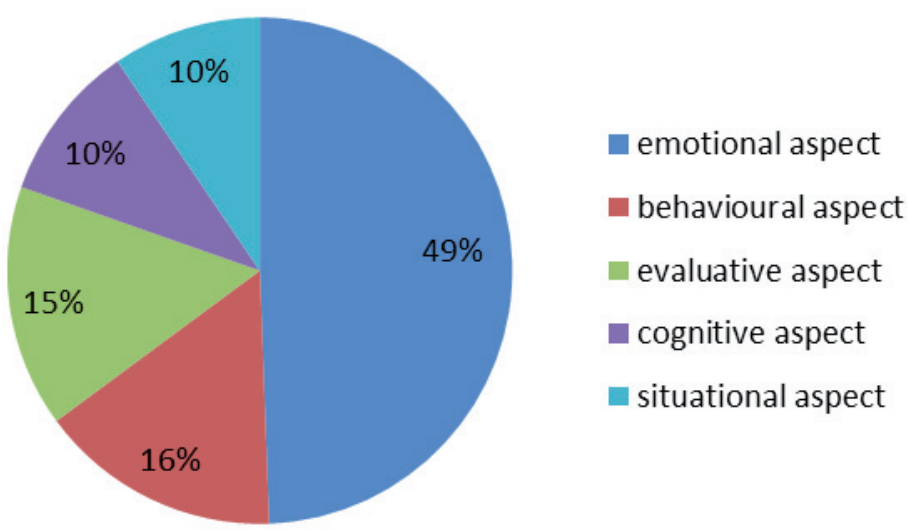

Chart 2. Percentage of each domain in self-compassion 
Table 1. Comparison of qualitative analysis for compassion and self-compassion after discarding categories with fewer than 5 associations

\begin{tabular}{|c|c|}
\hline Compassion 382 & Self-compassion 336 \\
\hline $\begin{array}{l}\text { Emotional aspect of compassion } 187 \\
\text { Empathy } 71 \\
\text { Word empathy } 54 \\
\text { Empathy towards others } 17 \\
\text { Emotions } 116 \\
\text { Synonyms of emotions } 8 \\
\text { Specific emotions } 108 \\
+ \text { Love } 26 \\
+ \text { Happiness } 7 \\
\text { - Sadness } 22 \\
\text { - Remorse } 34\end{array}$ & $\begin{array}{l}\text { Emotional aspect of self-compassion } 166 \\
\text { Empathy towards self } 10 \\
\text { Emotions towards self } 156 \\
\text { Specific emotions } 152 \\
\text { + Love } 31 \\
\text { + Calmness } 13 \\
\text { - Sadness } 22 \\
\text { - Remorse } 35 \\
\text { - Unhappiness } 12 \\
\text { - Anger } 6 \\
\text { - Vulnerability } 8\end{array}$ \\
\hline $\begin{array}{l}\text { Cognitive aspect of compassion } 44 \\
\text { Understanding } 44 \\
\text { General understanding } 40\end{array}$ & $\begin{array}{l}\text { Cognitive aspect of self-compassion } 34 \\
\text { Understanding } 25 \\
\text { General understanding } 13 \\
\text { Understanding self } 12 \\
\text { Balancing } 9\end{array}$ \\
\hline $\begin{array}{l}\text { Behavioural aspect of compassion } \mathbf{8 3} \\
\text { Display of help } 24 \\
\text { Help } 18 \\
\text { Support } 6 \\
\text { Display of favour } 54 \\
\text { Physical closeness } 10 \\
\text { Mental closeness } 44 \\
\text { Tenderness } 17 \\
\text { Care } 5 \\
\text { Goodness } 7 \\
\text { Companionship } 6 \\
\text { Display of motivation } 5 \\
\end{array}$ & $\begin{array}{l}\text { Behavioural aspect of self-compassion } \mathbf{5 2} \\
\text { Display of help towards self } 6 \\
\text { Display of favour towards self } 46 \\
\text { Self-forgiveness } 6 \\
\text { Self-support } 10 \\
\text { Self-care } 6 \\
\text { Self-assurance } 11 \\
\text { Self-acceptance } 8\end{array}$ \\
\hline $\begin{array}{l}\text { Biological aspect of compassion } \mathbf{5 9} \\
\text { People } 50 \\
\text { Types of compassionate relationships } 27 \\
\text { Family and close ones } 11 \\
\text { Vulnerable people } 5 \\
\text { Friends } 11 \\
\text { Types of compassionate situations } 23 \\
\text { Loss } 8 \\
\text { General suffering } 15 \\
\text { Disease } 6 \\
\text { Animals } 8 \\
\end{array}$ & $\begin{array}{l}\text { Situational aspect of self-compassion } 32 \\
\text { Types of external situations } 9 \\
\text { Types of internal situations } 23 \\
\text { Resulting from the inside } 14 \\
\text { Resulting from the interaction with others } 9\end{array}$ \\
\hline $\begin{array}{l}\text { Evaluative aspect of compassion } 9 \\
\text { General evaluation } 5\end{array}$ & $\begin{array}{l}\text { Evaluative aspect of self-compassion } \mathbf{5 2} \\
\text { Misunderstanding } 8 \\
\text { Related to self } 8 \\
\text { Negative evaluation } 19 \\
\text { Misuse of self-compassion } 14 \\
\text { Pointlessness of self-compassion } 5 \\
\text { Positive evaluation } 17 \\
\text { Connection with virtues } 11 \\
\text { Importance of self-compassion } 6\end{array}$ \\
\hline
\end{tabular}


( $\mathrm{f}=59 ; 15.44 \%)$ is third, followed by the Cognitive Aspect of compassion $(\mathrm{f}=44 ; 11.52 \%$ ) and the final domain, the Evaluative Aspect of compassion ( $\mathrm{f}=9 ; 2.36 \%$ ). For a comparison of the frequencies in each compassion domain see Chart 1.

The most frequent self-compassion domain was the Emotional aspect of self-compassion ( $f=166 ; 49.4 \%)$. The next two were equally represented: the Behavioural Aspect of self-compassion ( $\mathrm{f}=52 ; 15.48 \%$ ) and the Evaluative Aspect of self-compassion ( $\mathrm{f}=52$; $15.48 \%)$. They were followed by the Cognitive Aspect of self-compassion ( $\mathrm{f}=34 ; 10.12 \%)$ and the final domain was the Situational Aspect of self-compassion ( $\mathrm{f}=32 ; 9.52 \%$ ). For a comparison of the frequencies in each self-compassion domain, see Chart 2.

A comparison of the free associations for compassion and self-compassion is presented in Table 1. For clarity and concision we have included only categories with five or more associations.

\section{Discussion}

The aim of the study was to find out what participants associate with the words compassion and self-compassion and whether they conceptualise these associations more in terms of emotions, cognitions, or behaviours.

Despite the participants having been asked to write down their first three associations, we ended up with various numbers of associations for the two stimulus words. Given that there were 151 participants, ideally there would have been 454 associations if everybody had followed the instructions. However, there were 391 associations for compassion and only 351 associations for self-compassion. This could indicate that self-compassion is used less frequently and is consequently a less understandable term or that people were less willing to share their associations as self-compassion is more related to the self and therefore more personal.

The domains that resulted from the analysis of the first three associations for the word compassion were Emotional Aspect, Cognitive Aspect, Behavioural Aspect, Biological Aspect and Evaluative Aspect. Very similar domains emerged from the analysis of the answers for the word self-compassion. These were Emotional Aspect, Cognitive Aspect, Behavioural Aspect, Situational Aspect and Evaluative Aspect.

\section{Emotional aspect}

The most frequently represented domain for compassion and for self-compassion was Emotional Aspect, which is most fleshed out in terms of subdomains, categories, and characteristics for both stimulus words. The emotional states participants in our study associated with the words included both positive and negative feelings. This may contribute to the mixed nature of compassion, which is a mixture of negative emotions that are the result of suffering and positive feelings associated with the motivation to help a sufferer. The negative emotions to do with suffering associated with compassion were sadness and remorse, and to a lesser extent pain. Love and happiness were also mentioned by the participants and were included in the group of emotions with positive valence.

The emotional aspect of compassion and self-compassion was the most frequent and the richest domain, suggesting that people see compassion and self-compassion mainly 
as emotions. This domain consists of two subdomains- "Empathy" and "Emotions". Participants connected compassion with the affective component in particular: either with specific emotions or with empathy-resonance with the emotions of others. Klimecki, Leiberg, Lamm, and Singer (2012) discuss the difference between empathy and compassion from a neuropsychological point of view. In their experiment they found greater negative affect and the activation of the brain areas associated with resonance with other peoples' pain among participants who watched a video of suffering following empathy training. However, when the same video was watched after compassion training was conducted participants reported an increased positive affect and various brain areas were activated. They concluded that these socio-affective states are related, but also have significant differences that are indicative of their functions. The "Emotions" subdomain was made up of two categories: 1) "Synonyms for Emotions" and 2) "Specific Emotions". The first category contained associations relating to the general concept of emotion, like "feeling" or "sentiment". The second category was more specific. The "Specific Emotions" category includes specific emotions related to compassion. Negative emotions like "sadness", or "remorse" were dominant. In their study Goetz et al. (2010) refer to compassion as a distinct emotion which differs from sadness, distress, love, and other emotions. A compassionate facial expression used in a study by Keltner and Haidt (1999) was most frequently identified as sadness. Quite a lot of positive characteristics were found in our data for compassion, like "love" and "happiness", which partially supports the conclusion of Sprecher and Fehr (2005) that compassion could be a special kind of love. But the frequency of these associations was comparable with that of the negative characteristics, which could be interpreted as being a result of the fact that compassion is a mixed emotion. Compassion itself combines negative emotional aspects evoked by both situations of suffering and by emotions expressed by sufferers with whom we resonate emotionally. At the same time, compassion produces positive feelings brought about by helping behaviours. This positive feeling is our natural reward-physiological feedback in real time, a reaction to our behaviour towards a person in need of help (Ekman, 2014). The mixed nature of self-compassion can be seen in the mix of negative emotions brought about by suffering and the positive feelings associated with the relief of the suffering. Self-compassion was related to remorse, sadness, and unhappiness. On the other hand, self-compassion was connected to love and calmness. Interestingly, more emotional characteristics were found for self-compassion than for compassion. This could suggest that people are more emotionally involved with the self than with others. Not surprisingly, for both self-compassion and compassion, there were more free associations connected with negative emotions than with positive emotions. As compassion and selfcompassion are felt in distressful situations or even situations involving suffering, it is no wonder that people emotionally resonate with the discomfort experienced by the people involved-either their own or that of others.

\section{Behavioural aspect}

The second frequency domain for compassion and self-compassion was the identical Behavioural Aspect domain. Behavioural Aspect has three main subdomains when related to compassion and two subdomains when related to self-compassion, and there 
is a difference only in one subdomain. The subdomains for which compassion and selfcompassion are common are "display of help" and "display of favour". In compassion, there is an extra category, "display of motivation", which is relevant to Gilbert's theory (Gilbert et al., 2017). Not surprisingly, display of motivation does not appear in relation to selfcompassion because people are naturally driven to help themselves but need motivation to act compassionately towards others.

\section{Biological aspect}

The third most frequent domain for compassion was Biological Aspect, and for selfcompassion it was Evaluative Aspect. The biological aspect of compassion includes associations relating to living things. In addition to people, participants mentioned animals and in one case plants. In associations linked to human beings, relationships such as "friend" or "child" were mentioned, which is compatible with the evolutionary view that compassion has evolved to protect the weak (e.g., Goetz, Keltner, \& Simon-Thomas, 2010). As the target of self-compassion is the self, there is no need to specify who it is associated with, but there is a need to describe the situations in which self-compassion occurs in more detail. A similar domain is living organisms in the case of compassion and types of situations in the case of self-compassion. The participants described compassionate situations as those in which a person suffers.

\section{Evaluative aspect}

The Evaluative Aspect domain was also identified in the data relating to compassion and self-compassion. Interestingly, the Evaluative Aspect of compassion was less frequently represented than was the case with self-compassion, where the Evaluative and Behavioural Aspects are second most frequent. The reason more people evaluated self-compassion than compassion could be that it creates more cognitive dissonance, which they feel the need to explain or at least comment on. As Leary et al. (2007) have suggested, self-compassion leads people to understand their role in situations of distress without feeling negative emotions towards the self. Negative evaluation, which is another subdomain found in the data, may therefore be connected to a lack of personal experience of self-compassion.

\section{Cognitive aspect}

The Cognitive Aspect domain included understanding. In relation to compassion, this domain mainly comprises general understanding and understanding for others and within self-compassion it concerns understanding of the self. These could also be referred to as cognitive empathy, the term used by Bloom (2016). Compassion involves understanding suffering, and was expressed by the participants as "understanding" or "understanding others". In relation to self-compassion, the main category was "understanding self" and "general understanding", while a further category was "balancing", indicated by statements like "thinking about self" or "thinking about life". 


\section{Definitions of compassion and self-compassion}

The categories obtained from our data are similar to the definitions of compassion by Jazaieri et al. (2013) and Strauss et al. (2016), which state that compassion is an affective, cognitive, and behavioural process. We therefore consider compassion and self-compassion to consist of various aspects (Jazaieri et al., 2013; Strauss et al., 2016), as the data shows that the emotional aspect occurs most frequently and is possibly the most important domain for both constructs.

Both these definitions are relevant to self-compassion, with the only caveat being that it is directed towards the self and not other people. All five elements of the definition by Strauss et al. (2016) could be seen in our data. Recognition of suffering is present in the Biological Aspect of compassion and the Situational Aspect of self-compassion, which clearly indicate that people interpret it in terms of the suffering of the person. A feeling of empathy was frequently found in the data and so the whole subdomain is called empathy. The connection between empathy and living organisms as postulated in the theory by Strauss et al. (2016) is seen in the Biological Aspect domain. Tolerating uncomfortable feelings elicited in situations involving suffering were manifested in the data as negative emotional associations connected with compassion. The Behavioural Aspect was also evident in compassion, with participants reporting a general desire to help or concrete acts of helping like "hugging" or "supporting". The participants' answers on self-compassion mainly concerned helping and favouring one's self. The second element in the definition by Strauss et al. (2016) was not so clear in our data because of the complexity of the meaning and the simplicity of our data. However, there were humanity associations for both compassion and self-compassion in our data.

\section{Analysis of the most frequent associations}

In order to summarise our findings we described the most frequent associations for both constructs. We decided to include only categories containing at least 10 associations. The analysis showed that the participants saw compassion as mainly consisting of empathy; the emotions of love, sadness and remorse; cognitive understanding; behavioural displays of help; and physical or mental closeness. They thought compassion was mainly directed towards people close to them, such as family and friends, and vulnerable people. Compassion occurs in situations involving loss or any other kind of suffering. The participants saw selfcompassion primarily in terms of the positive emotions of love and calmness; the negative emotions of unhappiness, sadness and remorse; cognitive understanding; behavioural displays of helping oneself by providing self-support and self-assurance. Self-compassion mainly appeared in relation to internal suffering in response to criticism or externally in relation to difficult situations. Self-compassion was evaluated in both negative (because of its misuse) and positive terms (because of its connection to virtues).

\section{Limitations and future work}

We have focused on free associations produced in response to the words compassion and self-compassion. We limited these to the first three associations. The associations have 
limited reporting value and, as we had no opportunity to ask the participants for details, the statements could have been misinterpreted. To some extent, we solved this by using the Consensual Qualitative Research method of data analysis. As very little is known yet about what compassion and self-compassion mean to people, it is a promising area for further qualitative research. In our future work, we would like to use open-ended questionnaires, in-depth interviews, or focus groups to explore people's perceptions and experiences of compassion and self-compassion more deeply.

The fact that our sample comprised psychology students is another limitation. In the future it would be a good idea to analyse the free associations of a community sample and then compare the results. Also, it would be useful to use a quantitative methodology to test peoples' constructions of compassion and self-compassion, as evidence from this kind of research is still viewed more seriously than that obtained using a qualitative methodology (Masaryk \& Sokolová, 2012). In future, it would be useful to investigate what compassion and self-compassion are and whether there is a particular facial expression associated with these emotions as there are with other primary emotions.

\section{Conclusion}

The findings of our qualitative study support the idea that compassion is a multidimensional construct consisting of emotions, cognitions, and behaviours. The free associations elicited the same four domains for both compassion and self-compassion: the Emotional Aspect of compassion/self-compassion, the Cognitive Aspect of compassion/self-compassion, the Behavioural Aspect of compassion/self-compassion, and the Evaluative Aspect of compassion/self-compassion. The only domains that differed were the Biological Aspect of compassion and the Situational Aspect of self-compassion. As the target of self-compassion is the self, there is no need to specify who it is associated with, but the situations in which self-compassion occurs require more detailed descriptions. Where compassion is concerned a very similar domain focuses on different living organisms and on the types of situations in which self-compassion occurs.

The participants mainly viewed compassion and self-compassion in terms of emotions. The emotions were negative as well as positive, which suggests compassion may be a mixed emotion. Our study showed that the participants perceived compassion as consisting mainly of empathy; the emotions of love, sadness and remorse; cognitive understanding; behavioural displays of help; and physical or mental closeness. Compassion was mainly directed towards those close to them, such as family and friends, and towards vulnerable people. Compassion occurs in situations of loss or any other kind of suffering. The participants saw selfcompassion primarily in terms of the positive emotions of love and calmness; the negative emotions of unhappiness, sadness and remorse; cognitive understanding; and behavioural displays of helping the self by providing self-support and self-assurance. Self-compassion mainly occurs in situations of internal suffering because of criticism or externally because of difficult situations. Self-compassion is evaluated in both negative (because of its misuse) and positive terms (because of its connection to virtues). The participants described the behavioural aspect more in relation to compassion than in relation to self-compassion, as if it was more natural to turn emotions and cognitions into behaviours towards others, rather 
than oneself. In addition, the participants referred to more evaluative aspects in relation to self-compassion than in relation to compassion, suggesting that being compassionate towards the self is not as socially desirable and accepted yet and therefore, requires more justification. Research on free associations is just the first stage in the qualitative research which needs to be performed to obtain a better understanding of how people conceptualise the constructs of compassion and self-compassion.

\section{References}

Balslev, A., \& Evers, D. (2011). Compassion in the world's religions: Envisioning human solidarity. Berlin: Lit Verlag.

Bloom, P. (2016). Against empathy: The case for rational compassion. New York, NY: Harper Collins.

Chambers, R. (2002). Qualitative approaches: Self-criticism and what can be gained from quantitative approaches. Delhi: Permanent Black.

Duarte, C., Matos, M., Stubbs, R. J., Gale, C., Morris, L., Gouveia, J. P., \& Gilbert, P. (2017). The impact of shame, self-criticism and social rank on eating behaviours in overweight and obese women participating in a weight management programme. PloS one, 12(1), e0167571.

Ekman, P. (2010). Compassion versus emotions. UC Berkeley's Greater Good Science Center. Retrieved from https://www.youtube.com/watch?v=KdlgGBehZVw

Ekman, P. (2014). Moving toward global compassion. San Francisco: Paul Ekman Group.

Ekman, P., \& Ekman, E. (2017). Is global compassion achievable? In E. M Seppälä, E. Simon-Thomas, S.L. Brown, M.C. Worline, C. D. Cameron, \& J. R. Doty (Eds.). The Oxford Handbook of Compassion Science (pp. 41-49). Oxford: Oxford University Press.

Figley, C. (1995). Compassion fatigue: Coping with secondary traumatic stress disorder in those who treat the traumatized. London: Brunner-Routledge.

Gilbert, P., Catarino, F., Duarte, C., Matos, M., Kolts, R., Stubbs, J., Ceresatto, L., Duarte, J., PintoGouveia, J., \& Basran, J. (2017). The development of compassionate engagement and action scales for self and others. Journal of Compassionate Health Care, 4(4).

Goetz, J. L., Keltner, D., \& Simon-Thomas, E. (2010). Compassion: An evolutionary analysis and empirical review. Psychological Bulletin, 136(3), 351.

Haidt, J. (2003). The moral emotions. Oxford: Oxford University Press.

Hill, C. E. (2012). Consensual qualitative research: A practical resource for investigating social science phenomena. Washington, DC: American Psychological Association.

Jazaieri, H., McGonigal, K., Jinpa T., Doty, J. R., Gross, J. J., \& Goldin, P. (2013). A randomized controlled trial of compassion cultivation training: Effects on mindfulness, affect, and emotion regulation. Motivation and Emotion, 38(1), 23-35.

Keltner, D., \& Haidt, J. (1999). Social functions of emotions at four levels of analysis. Cognition \& Emotion, 13(5), 505-521.

Klimecki, O. M., Leiberg, S., Lamm, C., \& Singer, T. (2012). Functional neural plasticity and associated changes in positive affect after compassion training. Cerebral cortex, 23(7), 1552-1561.

Lazarus, R.S. (1991). Emotion and adaptation. Oxford: Oxford University Press.

Leary, M. R., Tate, E. B., Adams, C. E., Batts Allen, A., \& Hancock, J. (2007). Self-compassion and reactions to unpleasant self-relevant events: The implications of treating oneself kindly. Journal of Personality and Social Psychology, 92(5), 887.

MacBeth, A., \& Gumley, A. (2012). Exploring compassion: A meta-analysis of the association between self-compassion and psychopathology. Clinical Psychology Review, 32(6), 545-552.

Masaryk, R., \& Sokolová, L. (2012). Making a difference by doing applied qualitative research in education: Three case studies. Human Affairs, 22(4), 492-509. 
Neff, K. D. (2003). The development and validation of a scale to measure self-compassion. Self and Identity, 2(3), 223-250.

Neff, K. D., \& Germer, C. K. (2013). A pilot study and randomized controlled trial of the mindful selfcompassion program. Journal of Clinical Psychology, 69(1), 28-44.

Neff, K. D., Kirkpatrick, K. L., \& Rude, S.S. (2007). An examination of self-compassion in relation to positive psychological functioning and personality traits. Journal of Research in Personality, 41(4), 908-916.

Pauley, G., \& McPherson, S. (2010). The experience and meaning of compassion and self-compassion for individuals with depression or anxiety. Psychology and Psychotherapy: Theory, Research and Practice, 83(2), 129-143.

Seppälä, E. M., Simon-Thomas, E., Brown, S. L., Worline, M. C., Cameron, C. D., \& Doty, J. R. (2017). The Oxford Handbook of Compassion Science. Oxford: Oxford University Press.

Sirois, F. M., Kitner, R., \& Hirsch, J. K. (2015). Self-compassion, affect, and health-promoting behaviors. Health Psychology, 34(6), 661.

Sprecher, S., \& Fehr, B. (2005). Compassionate love for close others and humanity. Journal of Social and Personal Relationships, 22(5), 629-651.

Strauss, C., Taylor, B. L., Gu, J., Kuyken, W., Baer, R., Jones, F., \& Cavanagh, K. (2016). What is compassion and how can we measure it? A review of definitions and measures. Clinical Psychology Review, 47, 15-27.

van der Cingel, M. (2011). Compassion in care: A qualitative study of older people with a chronic disease and nurses. Nursing Ethics, 18(5), 672-685.

Zessin, U., Dickhäuser, O., \& Garbade, S. (2015). The relationship between self-compassion and wellbeing: A meta-analysis. Applied Psychology: Health and Well-Being, 7(3), 340-364.

Institute of Applied Psychology,

Faculty of Social and Economic Sciences,

Comenius University in Bratislava,

Mlynské luhy 4,

82105 Bratislava,

Slovakia

Email: julia.halamova@gmail.com 


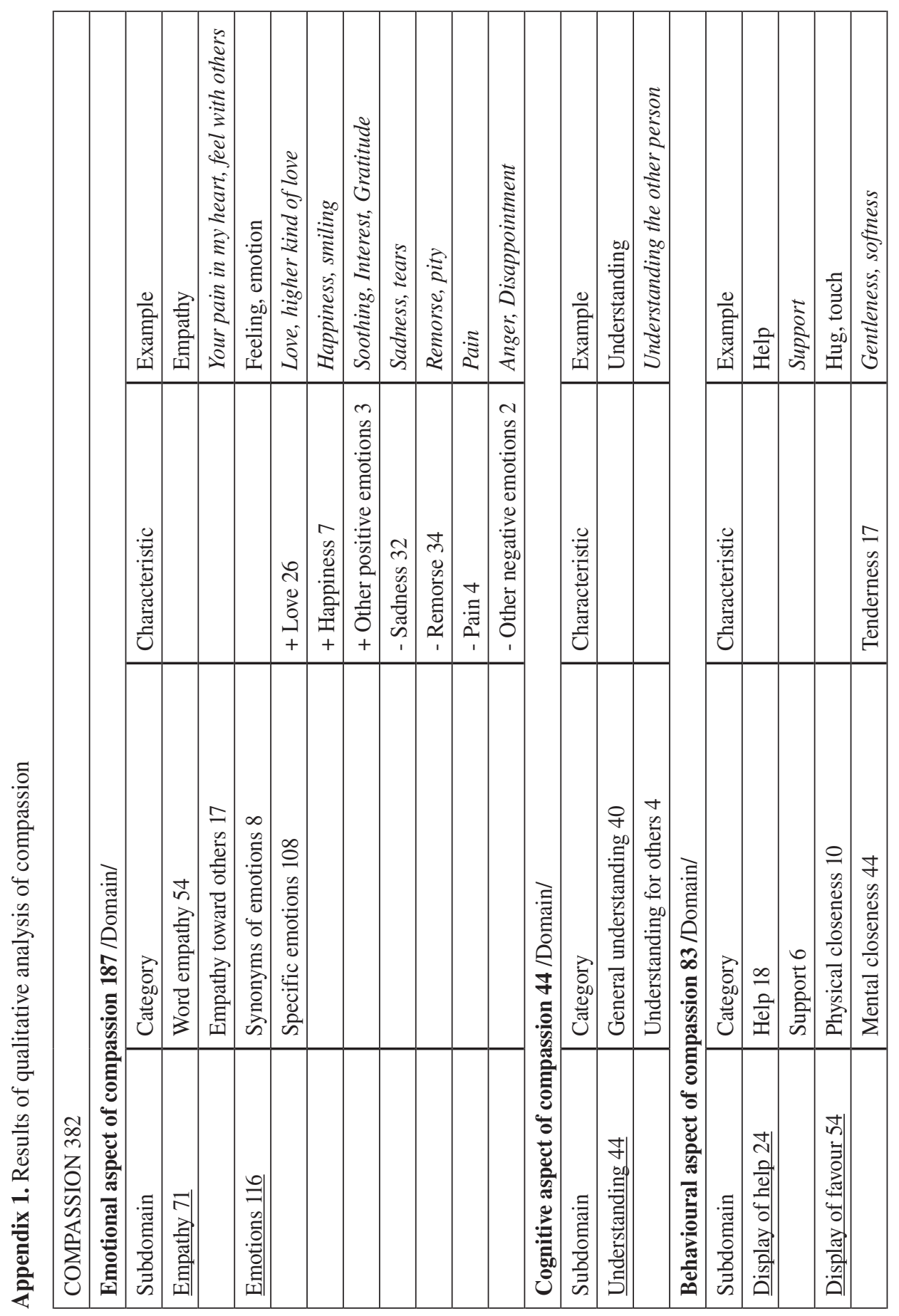




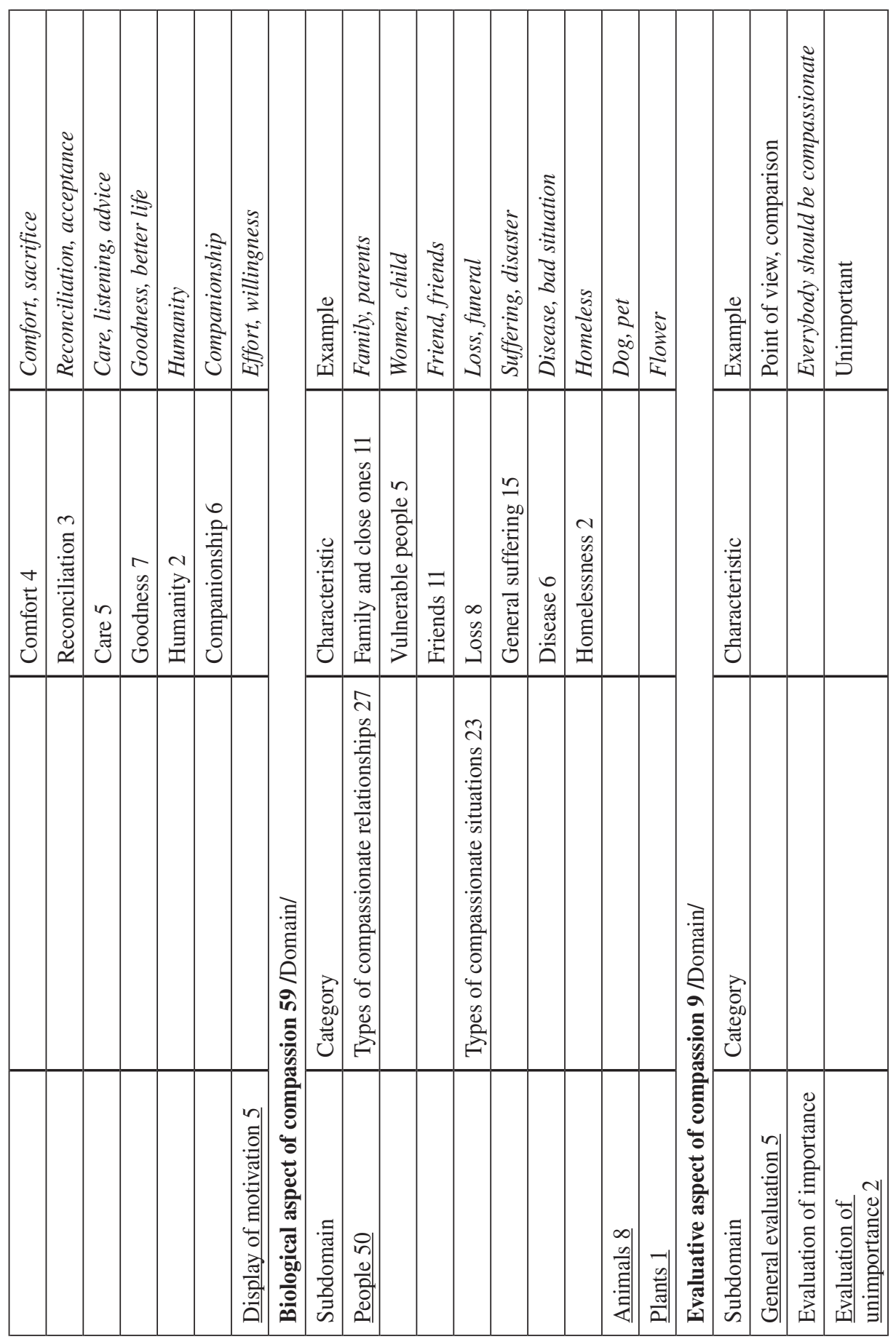




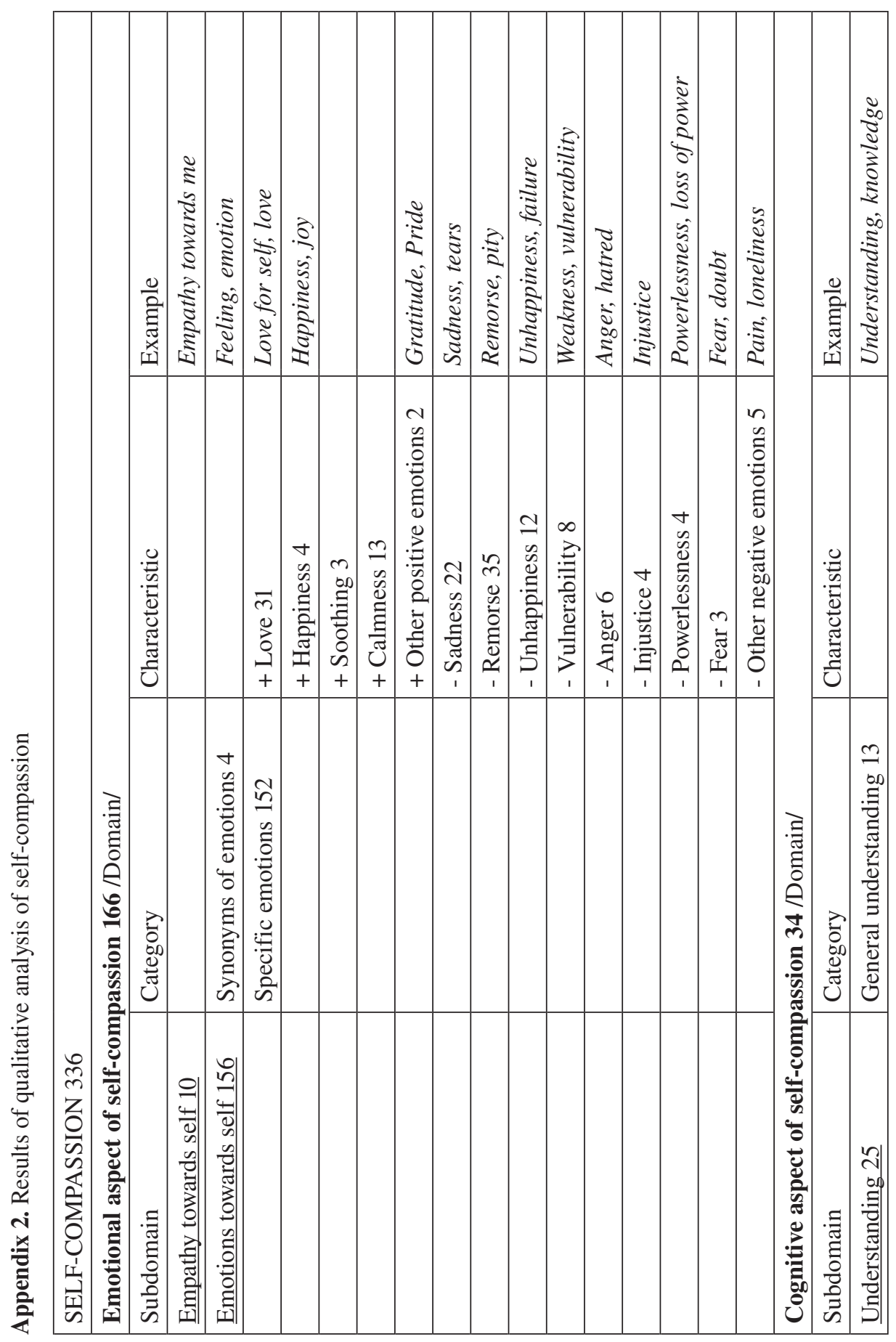




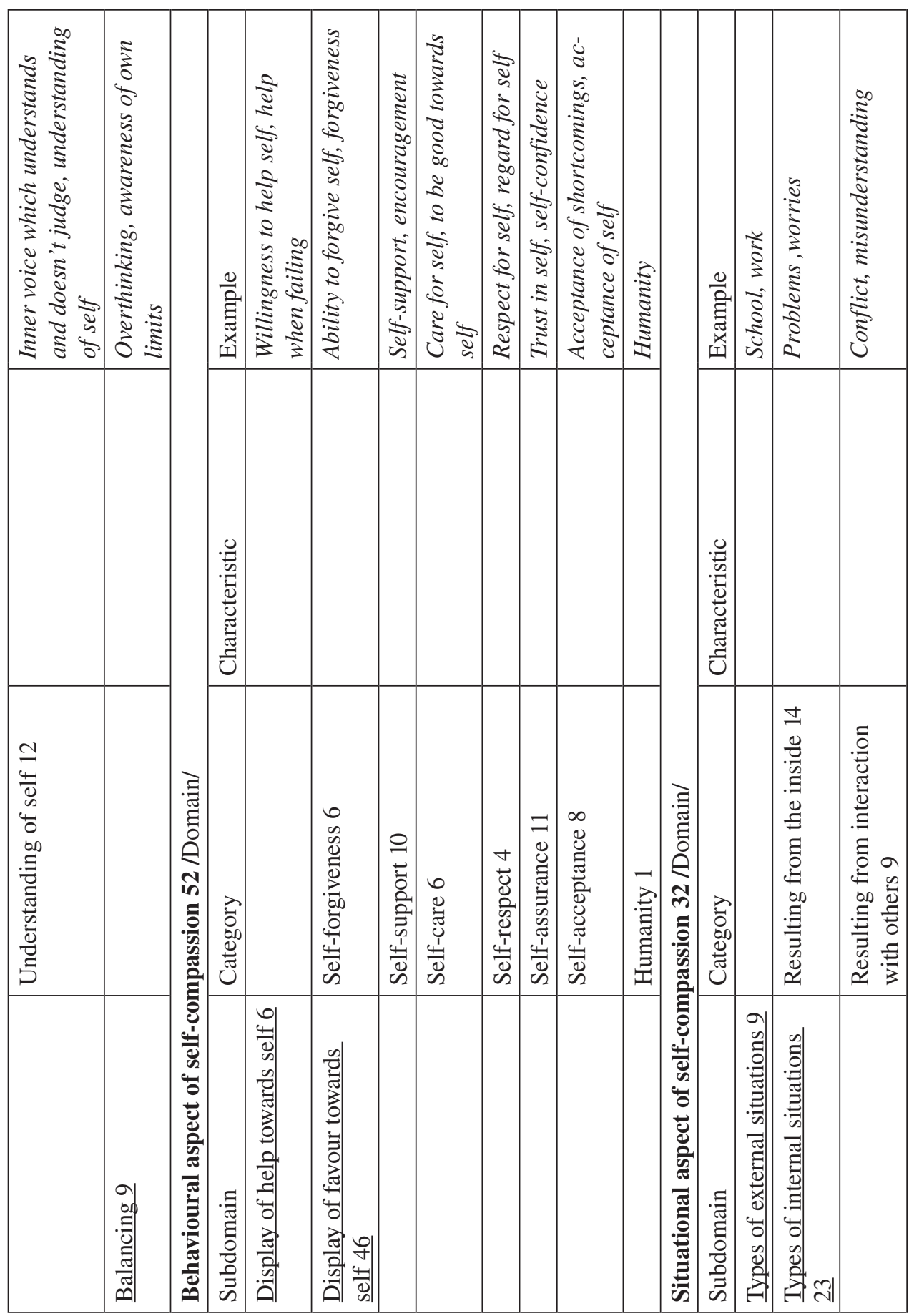




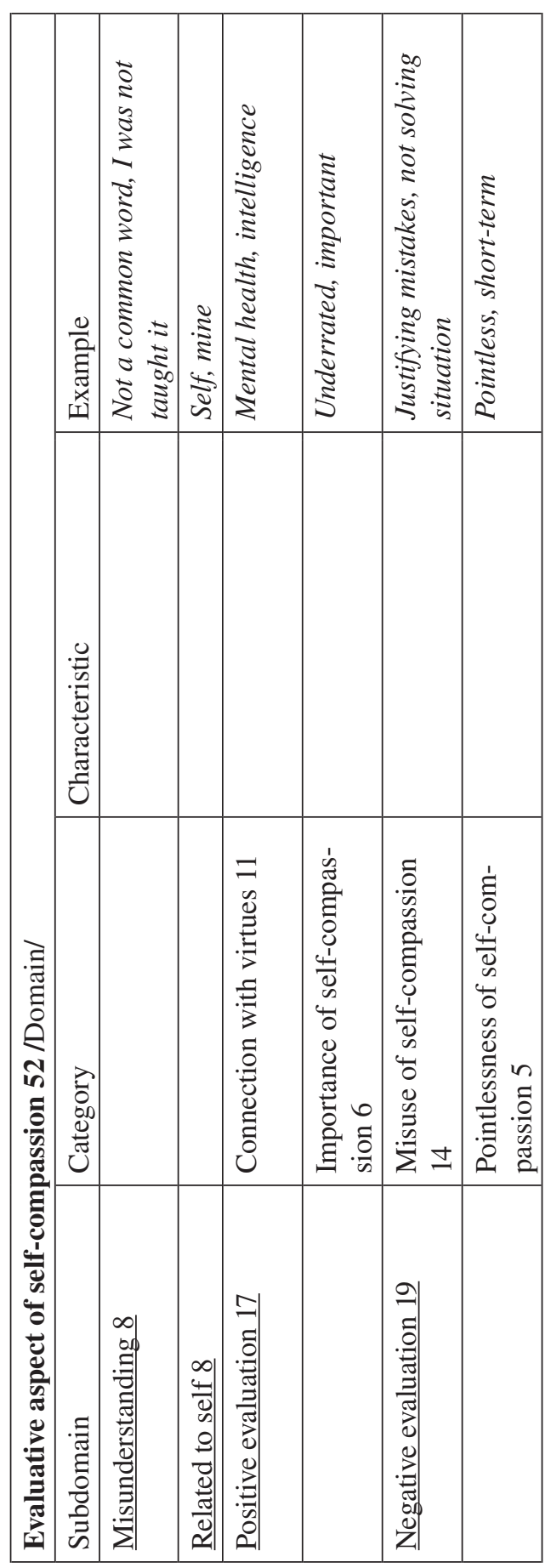

